\title{
El esoterismo en la obra del artista chileno Germán Mourgues B.
}

Esotericism in the work of the Chilean artist Germán Mourgues B.

Esaú Mourgues O.

Agrupación Cultural Germán Mourgues Bernard, Linares, Chile (esaumourgues@yahoo.com)

Recibido el 05 de diciembre de 2017; revisado el 10 de enero de 2018; aceptado el 18 de febrero de 2018 ; publicado el 21 de marzo de 2018

RESUMEN: El artista Germán Mourgues B., debido a las circunstancias socio-políticas que vivió Chile a partir de 1973, desarrolla su obra al margen de los circuitos oficiales del arte. Creando lejos de corrientes, modas o estilos, un interesante trabajo que aún no ha sido suficientemente relevado en el país. Intentó - transversalmente - el rescate de la cultura vernácula, tomando leyendas, mitos y expresiones iconográficas locales e indagando en ellas lo que hay de universal. Se cruzan, en su obra, estos temas con los del gnosticismo, lo esotérico y la alquimia. Haciendo uso de distintos medios de expresión crea una obra de gran riqueza de contenidos y profunda originalidad. En este trabajo se analiza, desde los símbolos, su obra pictórica creada en la última década de su vida (una de sus facetas menos conocidas $)^{1}$, posibilitando a través de ella el acceso a su personal cosmovisión.

PALABRAS CLAVE: Germán Mourgues, pintura, hermenéutica, símbolos, alquimia.

\begin{abstract}
The artist Germán Mourgues B., due to the socio-political circumstances that Chile lived from 1973 develops his work to the margin of the official circuits of the art. To create, away from currents, fashions or styles, an interesting work that has not been sufficiently relieved in the country yet. He tried - transversely - the rescue of the vernacular culture, taking legends, myths and local iconographic expressions and investigating what exist of universal in them. These topics cross, in its work, with those of the gnostic, the esoteric and the alchemy. Making use of different ways of expression he creates a work very rich in content and deep originality. In this work is analyzed, from the symbols, his pictorial work created in the last decade of his life (one of his least well-known facets), making possible through it the access to his personal world view.
\end{abstract}

KEYWORDS: Germán Mourgues, painting, hermeneutics, symbols, alchemy. 
El presente trabajo se origina a partir de las iniciativas de rescate, conservación y puesta en valor del legado artístico-cultural de Germán Mourgues, iniciadas con la creación de la "Agrupación Cultural Germán Mourgues Bernard” en enero del año 2016. Este estudio busca alcanzar dos propósitos: por una parte, contribuir a la puesta en valor de su obra multidisciplinaria; por otra, demostrar a través del análisis y la reflexión, la radical originalidad de su obra y el profundo contenido simbólico que ocultan las imágenes aparentemente coloquiales de su producción artística.

Para ello, presentaremos algunos antecedentes biográficos de este artista que vivió y creó en los márgenes de los sistemas oficiales (educativo, político, religioso, etc.) que explican la singularidad de su obra y el "silencio" en que ha permanecido. Las fuentes bibliográficas sobre Mourgues son escasas, por lo que la totalidad de este apartado estará basado en fuentes primarias obtenidas de sus descendientes.

A continuación, se describirán las características de su obra pictórica, actividad a la que se dedicó durante la última década de su vida. Examen que se abordará básicamente desde los aspectos técnicos y formales de su pintura, buscando evidenciar la originalidad de su trabajo. Luego se profundizará la investigación a través del análisis de una obra específica ahondando en sus contenidos, lo que permitirá develar su gran riqueza simbólica, que, junto a la señalada originalidad formal, justifican el rescate y puesta en valor de este artista.

En el aspecto metodológico, esta “aproximación” a la pintura de Mourgues se realizará desde el enfoque teórico de Erwin Panofsky y su modelo de análisis iconográfico, que señala que las obras de arte tienen varias lecturas e interpretaciones, al tiempo que plantea tres niveles de análisis de lectura; como una primera etapa de análisis, el "significado fáctico y el expresivo" (preiconográfico), en el que se estudia la imagen de manera descriptiva; otro significado sería "secundario o convencional" (iconográfico), y señala un estudio sobre historias o alegorías en las imágenes; por último, propone una nueva fase, el "significado intrínseco o contenido", donde la imagen se estudia en profundidad y en relación con valores simbólicos (Panofsky,1979, pp. 45-50). Por otro lado, en este análisis, se recurrirá al amplio repertorio de símbolos conservados por los estudiosos de las "ciencias" esotéricas para la lectura de los empleados por Mourgues en su obra.

Esta propuesta metodológica se justifica en función del manifiesto interés observado en Mourgues por los temas de carácter esotéricos como el gnosticismo y la alquimia. Enfatizando en el proceso, más que los propósitos historiográficos del método, los de carácter semiótico frente a la obra. 


\section{El $\operatorname{artista}^{2}$}

Germán Mourgues Bernard (1916-2000) nació en Linares, Chile, el 20 de junio de 1916. Hijo de inmigrantes franceses, pasó gran parte de su vida en su ciudad natal. Estudió en la Escuela de Artes y Oficios en Santiago (1937), donde fue alumno, entre otros, de Samuel Román Rojas ${ }^{3}$. Se retira prematuramente de la Escuela, adquiriendo, desde entonces, su cultura y visión del mundo de manera autodidacta.

Tras abandonar su educación formal, trabajó en la reconstrucción de la ciudad de Chillán destruida por el terremoto de 1939, época en la que con su hermana Noemí, realizan un relieve mural en el edificio del diario "La Discusión”, integrándose también (1941 a 1942) al equipo de colaboradores de los muralistas mexicanos Xavier Guerrero y David Alfaro Siqueiros en las obras que estos realizaron, en la Escuela México ${ }^{4}$.

De regreso en Linares, realizó un importante número de trabajos artísticos y de ornamentación, entre ellos, los capiteles de la nave central de la catedral y algunos relieves de estilo neoclásico en la casa de un notable vecino linarense. Realizó también trabajos en colaboración con el pintor Pedro Olmos, entre otros; el relieve para la tumba del obispo Roberto Moreira M. en la cripta de la Catedral, los relieves en cerámica para la "Gota de Leche” y un relieve en bronce para la tumba de otro destacado ciudadano linarense.

En las artesanías se propuso el rescate de algunas expresiones iconográficas de la cultura mapuche, específicamente el "Pillán" 5 , realizando múltiples versiones en diversos formatos y materiales, la mayoría en piedra. Algunas de estas obras se convirtieron en esculturas con las que obtuvo distinciones y premios ${ }^{6}$. En esta técnica incursionó en materiales diversos, (dientes de cachalote, hueso y conchas de moluscos), realizando obras que se situaron siempre entre la creación pura de inspiración vernácula y la artesanía entendida en su sentido tradicional.

\footnotetext{
${ }^{2}$ Las referencias bibliográficas sobre Mourgues son escasas, entre otras: QUIJADA, Mario (1988). Pinceladas históricas de Linares. Ed.Municipal: Linares (pp. 223-225), QUEVEDO, Manuel (2016) Crónicas de Linares. Ed. El Heraldo: Linares (pp.33-34), Colville, J. G. (2012). LA FUNDACIÓN Y EL FUNDADOR DEL LICEO DE TALCA, EN 1840. Boletín de la Academia Chilena de la Historia, 78(121), 133-174.

${ }^{3}$ Escultor Chileno, Premio Nacional de Artes (1964).

${ }^{4}$ El 28 de Mayo de 2004, mediante el Decreto Supremo No 331 y con la presencia del

Ministro de Educación Sergio Bitar, fueron declarados Monumento Nacional de Chile y patrimonio cultural.

${ }_{5}^{5}$ Deidad tutelar de los Mapuches (hombres de la tierra), uno de los pueblos originarios de Chile.

${ }^{6}$ Primer premio en el Salón Regional organizado por la Casa del Arte de Talca el año 1958.

Premio de Honor en el mismo certamen el año 1960.

Es distinguido con la medalla Picasso otorgada por la UNESCO.
} 
Su particular visión del mundo, su singular personalidad y una vasta obra de profunda originalidad lo condujeron a constituirse en un "personaje" en la comunidad linarense, convirtiéndose en un maestro, al cual acudieron espontáneos discípulos. Finalmente, en la década de 1990 y hasta su muerte se acercó a la pintura, en la que prolongó su temática y tradujo a las dos dimensiones lo que ya constituía su consolidado lenguaje plástico, su forma de expresión, su estilo.

Es necesario enfatizar, reiterándolo, en virtud de la comprensión de su obra, el interés permanente manifestado por Mourgues respecto a temas esotéricos, especialmente por la alquimia en la que el hombre de nuestra época no ve más que un quehacer pseudocientífico, en el que el alquimista pretendía convertir cualquier metal en oro. Sin embargo, para Eliade y Jung, entre otros estudiosos, la alquimia es una valiosa fuente de conocimientos místicos, filosóficos y psicológicos sobre el ser humano y su crecimiento espiritual. Esta es mucho más que el antecedente primitivo de la química moderna, y va muchísimo más allá del mundo físico para penetrar en las profundidades del inconsciente humano. La ciencia alquímica ofrece, al que sabe interpretar sus secretos, verdades que involucran la esencia misma del hombre, lo más profundo de su vida psíquica. Mircea Eliade al referirse al tema señala que la sociedad actual tuvo que sacrificar al progreso tal vez lo mejor de su alma (Eliade, 1983, p. 6). Por otra parte, Jung considera que la alquimia pervive en nuestro inconsciente.

\section{Su obra pictórica}

Son cuadros de mediano formato en los que utilizó la técnica del oleo sobre soportes de arpillera o madera. Entre las constantes formales de su pintura destacan el tratamiento de la figura humana (elemento central) sometida a una extrema y extraña simplificación. Son figuras muy alargadas y facetadas en planos en las que se percibe un especial énfasis en manos y pies (en ocasiones con más de cinco dedos) y en los ojos (a veces tres). Deformaciones que la convierten en esquema conceptual destinado a la representación de una realidad que está más allá de lo terrenal [1].

Es notable también el poderoso ritmo que crea las posturas contorsionadas de las figuras y su enrevesada disposición en una suerte de arabescos. Las figuras, de grandes dimensiones en relación al espacio pictórico, están siempre situadas en primer plano y dispuestas en una estructura compositiva que alude habitualmente a la circularidad [ 2 y 3]. La línea es vigorosa y con primacía de curvas envolventes que generan fuerzas centrífugas y centrípetas que se equilibran en el centro de un espacio pictórico que apenas aloja a los personajes. 


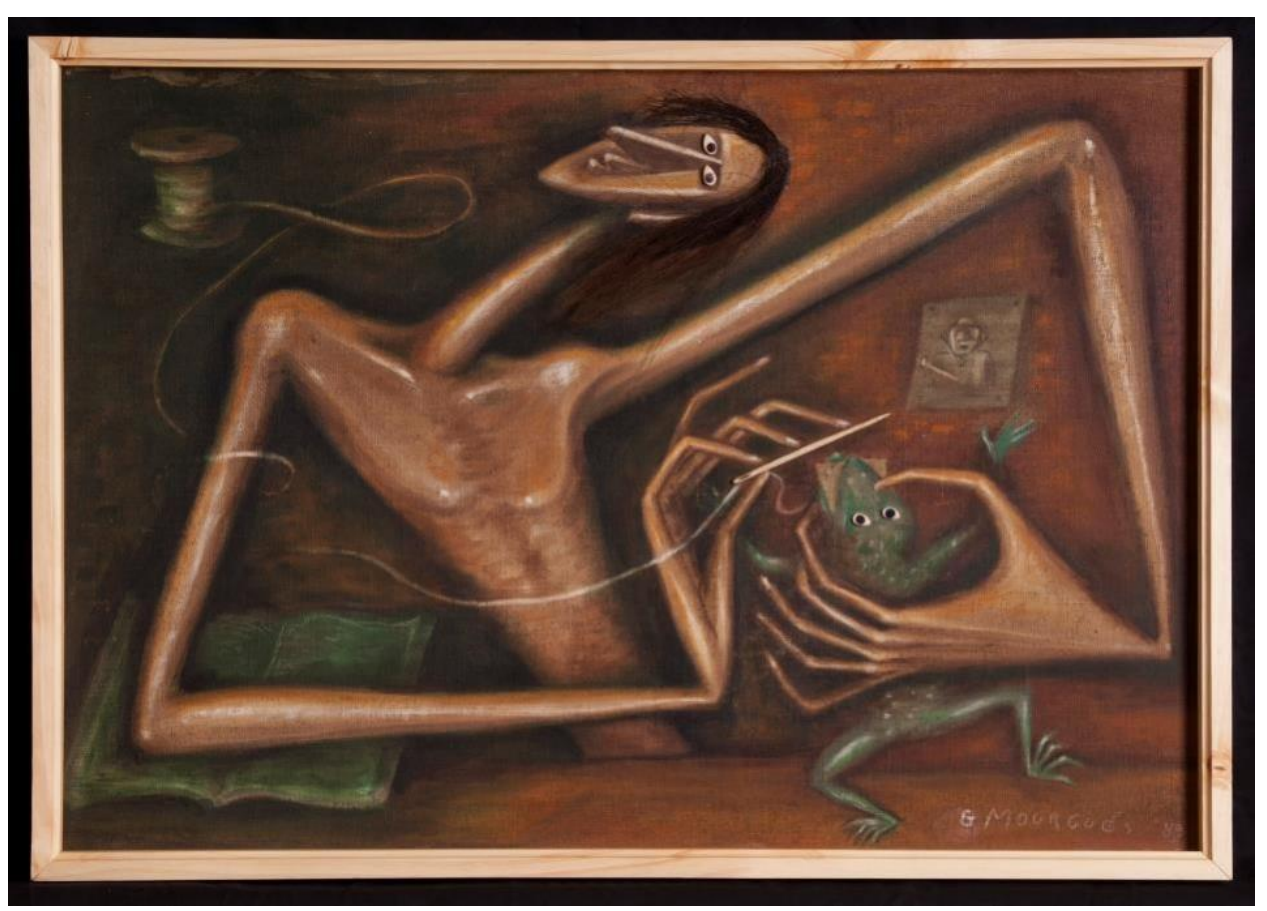

1. El embrujo del sapo (1992), 56 X $81 \mathrm{~cm}$. Óleo sobre arpillera y aplicaciones: Ojos de nácar y hueso, pelo de crin, aguja de hueso.

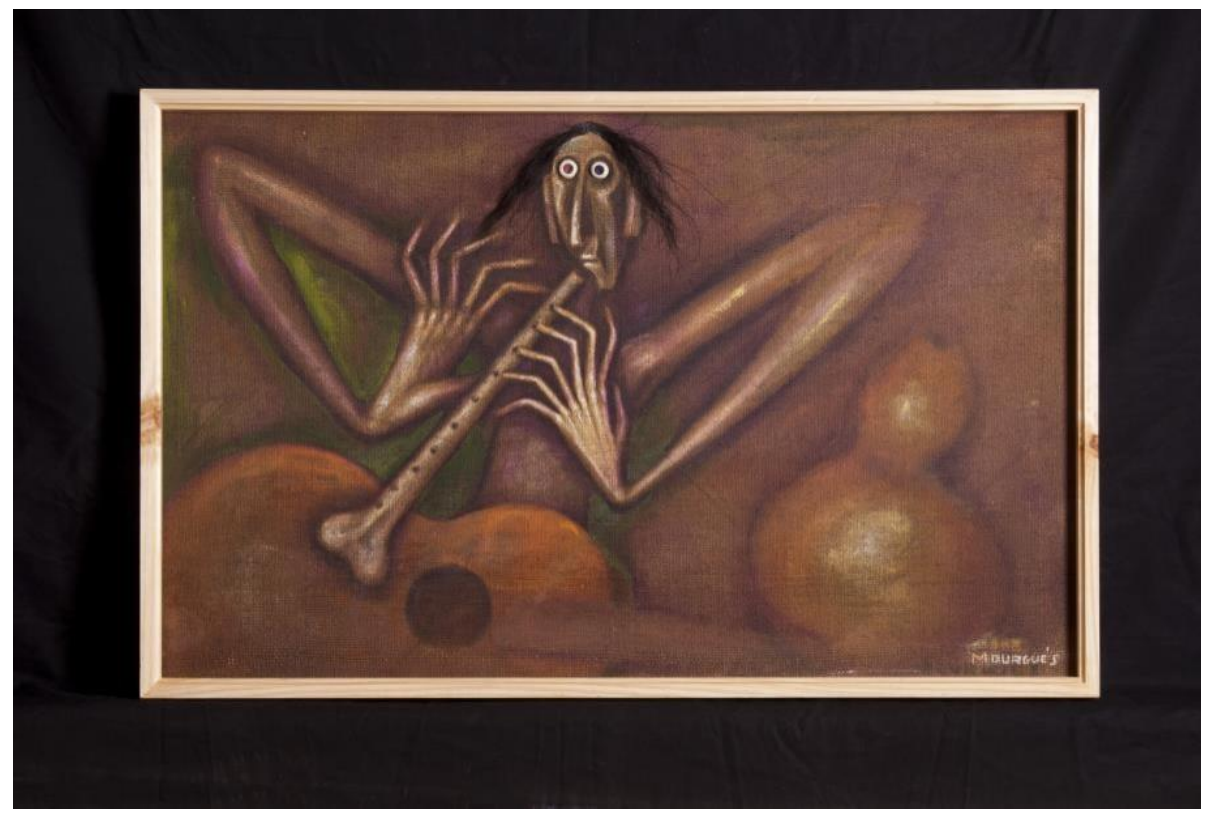

2. La flauta de canilla humana ( $\sin$ fecha), 58 X $93,5 \mathrm{~cm}$. Óleo sobre arpillera y aplicaciones: Ojos de hueso y nácar y pelo de crin. 


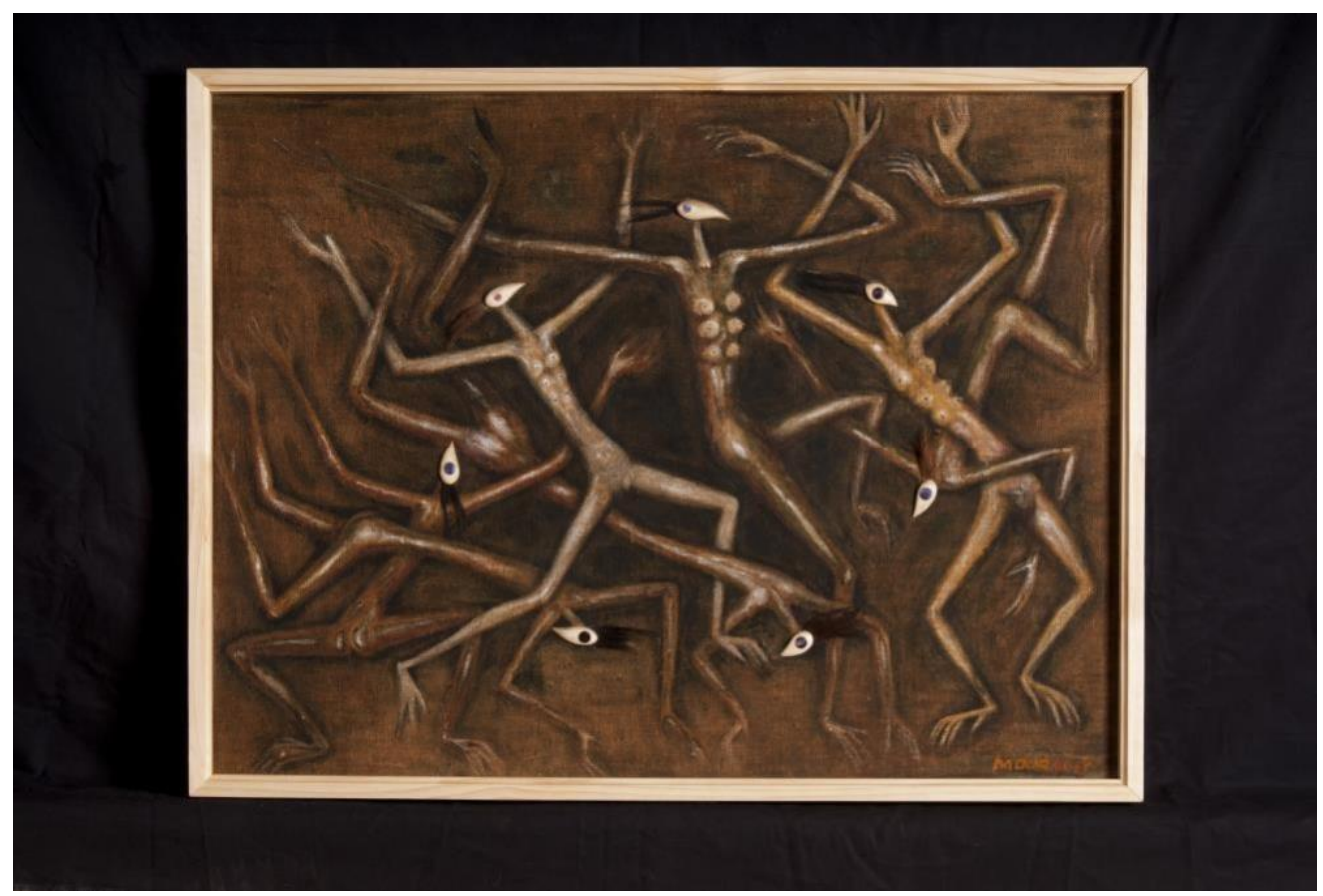

3. Danza de brujas (sin fecha), 57 X $84,5 \mathrm{~cm}$. Óleo sobre arpillera y aplicaciones: Cabezas-ojo de hueso y nácar, pelo de crin.

En relación al color, se trata de una "pintura" generalmente monocromática, amenizada por algunas notas de color, lo que obedece por una parte a la técnica de trabajo en que utiliza generalmente como soporte, arpillera de factura tosca y burda (sacos en desuso), utilizada sin imprimante conservando en algunas zonas de la obra el color del soporte. A ello se suma también el hecho de que el autor, escultor por formación y temperamento, violenta su naturaleza al trabajar el color. Sin embargo, lo fundamental de esta "monocromía" obedece a una intensión expresiva, que se vería debilitada por el uso de éste. Otra característica peculiar es la inclusión de elementos extra pictóricos, construidos ex profeso y aplicados en; ojos (hueso y nácar), adornos corporales (cobre o hueso) y pelo (estopa, crin o cabello humano), logrando estos elementos gran armonía con lo monocromático y constituyéndose en centros de interés que enfatizan su carácter expresionista.

Respecto al tratamiento del espacio, siendo una pintura figurativa, es notoria su renuncia a la línea de tierra como elemento esencial de la representación del espacio. Esto no significa que sea una pintura bidimensional, sino que el espacio es indefinido y no contextualiza las figuras en un ambiente determinado. No es tampoco que ignore compositivamente el fondo, pues lo trata como una contraforma que trabaja con la misma dedicación y vigor que las figuras creando la sensación de profundidad a través del uso de escorzos exagerados y del tratamiento de la luz que genera una atmosfera tenebrista. Los personajes operan en un contexto, peculiar, infinito e indefinido, de 
ausencia de las nociones de tiempo y espacio, convirtiéndose por ello en seres también atemporales y universales. Es un espacio que no está en ninguna parte, en el que no existe ni principio ni fin, ni aquí ni allá, ni ayer ni mañana, lo que sugiere la idea de eternidad.

Es en la aproximación hermenéutica donde se revela el valor de su repertorio iconográfico, dejando ver una narrativa que va más allá de lo fenoménico y que alude, en este discurso visual, a una cosmovisión, a una episteme, de carácter metafísica propia de las ciencias herméticas y que Mourgues entrecruza con la mitología, la leyenda, el chamanismo y la brujería local.

La obra de Mourgues, es producto de la búsqueda de respuestas a las grandes y eternas preguntas sobre el mundo y la existencia humana, y expresa estas reflexiones a través de un lenguaje plástico cargado profusamente de símbolos. Por tanto, su decodificación e interpretación exige pensar el valor simbólico de las imágenes, adquiriendo en este ejercicio toda su riqueza [4].

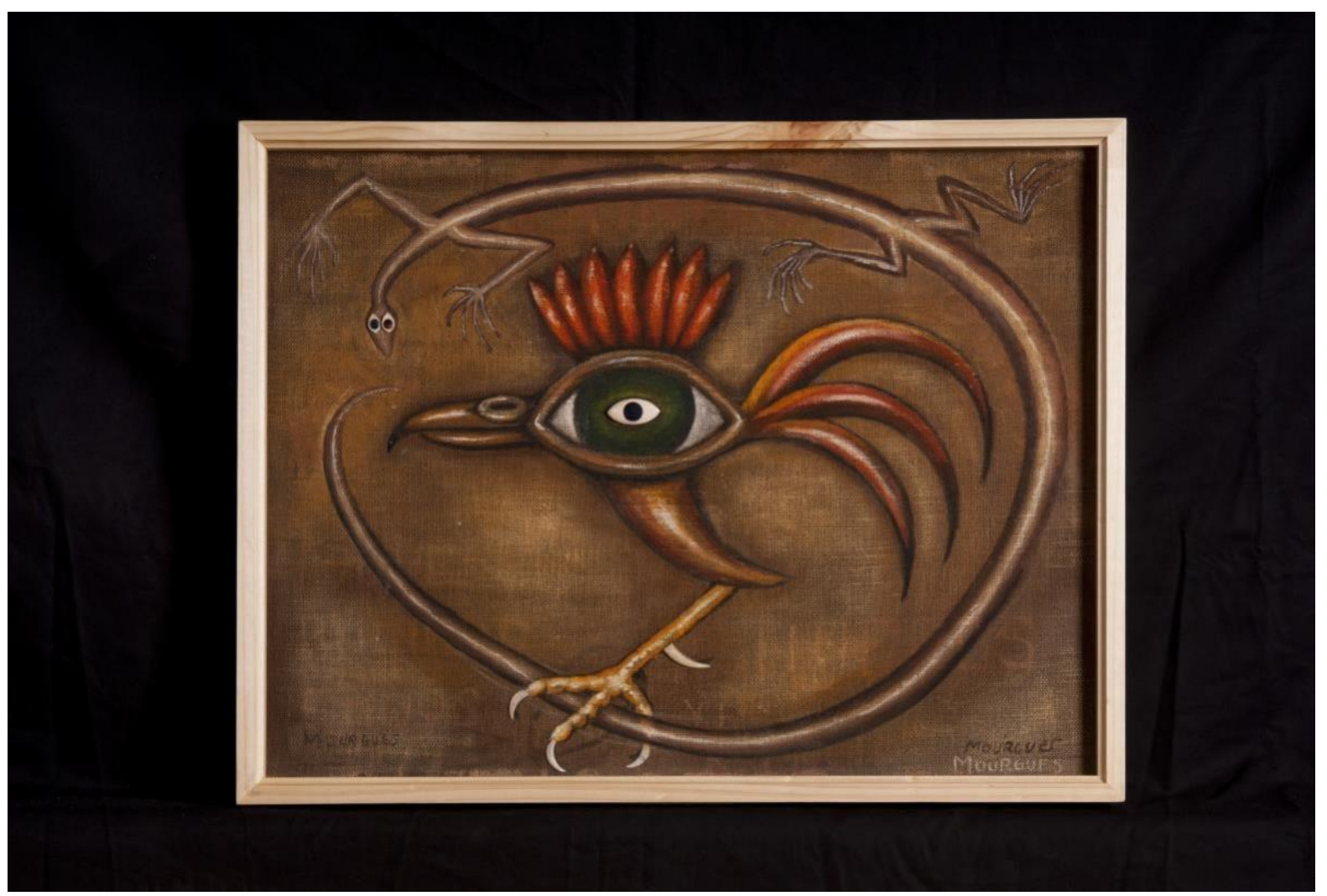

4. Engendro de gallo y culebrón ( $\sin$ fecha), 43 X $60 \mathrm{~cm}$. Óleo sobre arpillera y aplicaciones: Ojos de nácar y hueso.

Así lo demuestra el análisis de sus pinturas, especialmente una de las últimas — si no la última - que realizó antes de su muerte. "El sueño del alfarero", que es aparentemente la síntesis de 
sus reflexiones y una de las pocas obras en las que recupera el color y renuncia al empleo de las aplicaciones de otros materiales que caracterizó este periodo.

\subsection{Una interpretación}

El título de la obra "El sueño del alfarero", alude de forma obvia a lo percibido en una primera lectura. Sin embargo, es posible sostener que además de aquello que aparece como evidente, hay algo de mayor espesor en ella. En este sentido el título más que guiar en su lectura desvía la atención cerrando la obra — quizás deliberadamente — a una interpretación más profunda [5]. 


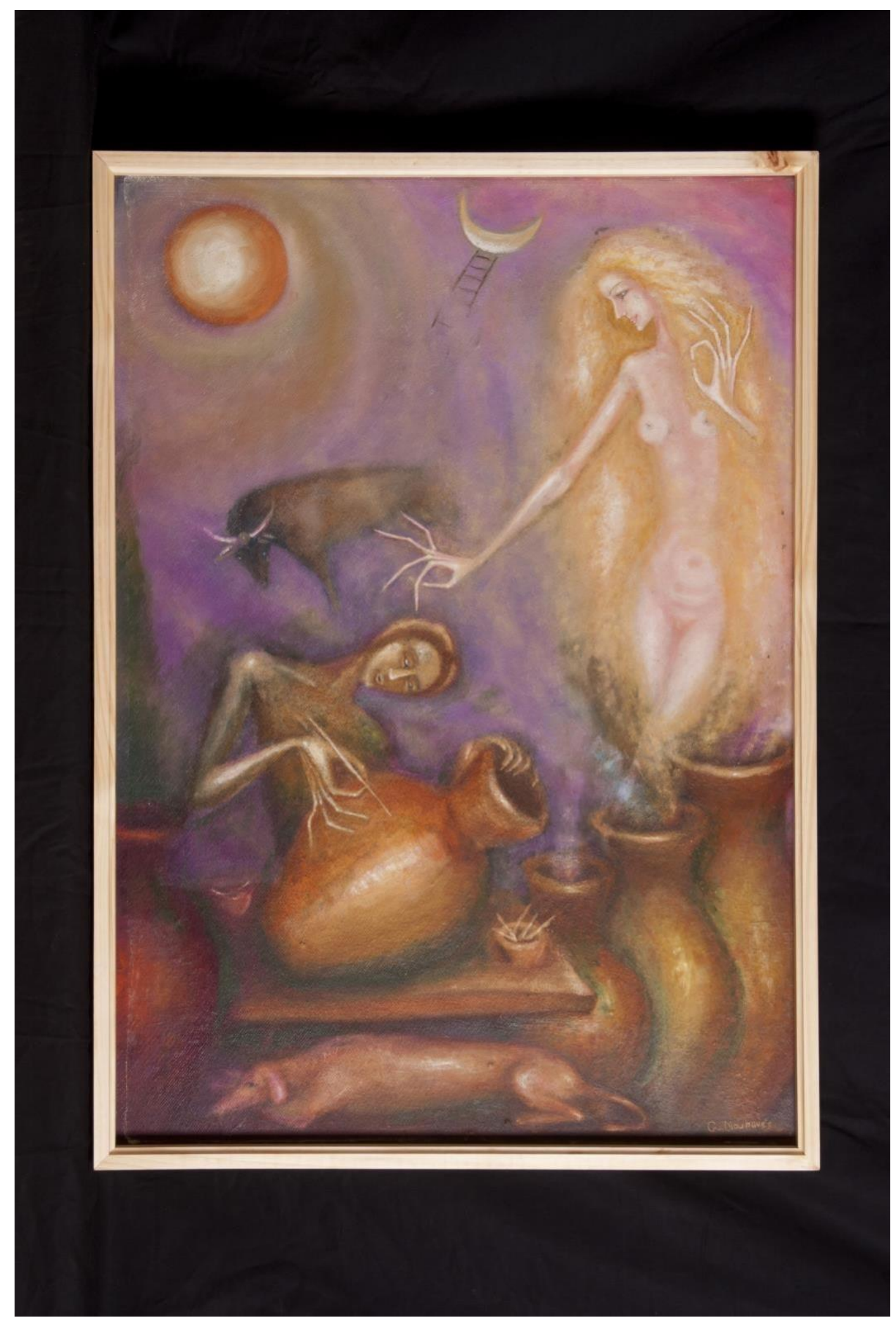

5. El sueño del alfarero ( $\sin$ fecha), $63 \times 90 \mathrm{~cm}$. Óleo sobre madera.

Al inventariar los elementos de la composición, se observan en el primer plano la figura de un hombre absorto en el modelado de unas ánforas o tinajas y la figura de una mujer que, como 
etérea aparición, emerge desde tres tinajas ubicadas al lado izquierdo. La mujer toca delicadamente con el índice de su mano derecha la cabeza del "artesano" (mientras la otra mano esboza un mudra) que absorto en su tarea parece no darse cuenta del gesto de la mujer. A los pies del hombre y bajo su banco de trabajo (casi sosteniéndolo) un perro parece dormir. Además de las figuras señaladas, que podrían considerarse como los elementos centrales de la composición hay, en un ambiguo segundo plano; un toro, la luna, el sol y una escalera.

En la composición el espacio es tratado de forma irreal y las figuras flotan en una atmósfera indiferenciada de tonalidades violetas y malva, sin que exista un fondo que las contextualice. Llama la atención significativamente la situación de aislamiento en la que permanecen los personajes en la escena. Todos estos seres parecen estar ensimismados en su propio mundo, en una actitud de indiferencia en relación al contexto, no estableciendo vínculos de comunicación entre sí ni con el entorno, a excepción de la mujer que al emerger en una especie de vapor o humo desde de las tres vasijas (enfatiza su irrealidad) observa al "artesano" estableciendo un vínculo a través del gesto y la mirada.

La enumeración descriptiva no dice gran cosa más allá de que a partir de ella se puede colegir que el artesano es efectivamente un artesano, y suponer que la mujer (aparición) es una musa que representa la inspiración. Sin embargo, bajo esta lectura además de quedar sin explicación lo que representa el resto de los elementos del cuadro, surge la legítima pregunta de si no habría sido más adecuado expresar el supuesto tema — la inspiración — a través de la figura del artista que es a quién (de acuerdo a la tradición) asisten las musas en el acto creativo, mientras que al artesano lo identificamos más con la conservación y reiteración de soluciones tradicionales.

Lo que parece claro - el título así lo declara - es que se trata de una imagen onírica, la que podría interpretarse de dos formas: entendiendo el sueño como la totalidad de lo representado o al artesano como un ser real rodeado de sus ensoñaciones mientras se entrega a su trabajo. Hasta aquí es todo lo que permite concluir la aproximación pre- iconográfica.

Al interpretar la pintura desde el simbolismo de sus elementos (trabajo, hombre, mujer, jarrón, perro, toro, sol, luna, escalera, cabellera, desnudez, manos, niebla), ésta adquiere mayor coherencia y su contenido se enriquece. La obra al representar a un alfarero empeñado en un trabajo monótono y repetitivo que demanda paciencia y constancia, podría considerarse aludiendo simbólicamente a la alquimia. Como señala Cirlot este tipo de trabajo podría homologarse a “...la labor lenta y paciente del alquimista que espera la transmutación menos de sus operaciones que de su 
actitud espiritual respecto a ellas y de su don de sí mismo a la empresa que realiza" (Cirlot, 1992, p. 447). Mourgues durante gran parte de su vida manifestó un especial interés por los temas esotéricos por lo que esta lectura no estaría desencaminada.

La mujer que emerge desde la izquierda del artesano, lo hace desnuda. El cristianismo medieval entendió la desnudez de dos formas; "nuditas virtualis" y "nuditas criminalis”. En este caso el símbolo se presenta más como "nuditas virtualis", que de acuerdo a Cirlot significa pureza e inocencia identificada con belleza moral y espiritual más que con lujuria o vanidosa exhibición, sentido que es reforzado por la larga y abundante cabellera dorada que simbólicamente se relaciona con lo solar y la idea de evolución espiritual (Cirlot 1992. p.168).

Con la presencia de los personajes protagónicos Mourgues instala la dualidad de lo masculino y femenino. Reiterándola luego en el segundo plano con la presencia del sol representación de lo masculino activo y fecundante, y la luna con su carácter pasivo húmedo y femenino. Dualidad que en las ciencias herméticas alude al principio de la "coincidentia oppositorum". Dualidad permanente en el cosmos y consecuentemente también en el hombre. Por otra parte, es posible ver, siguiendo a Jung, a la mujer en esta pareja como símbolo del "ánima" (parte femenina en el inconsciente masculino) en cuyo caso el contenido sugerido sería lo que la alquimia llamó "matrimonio interior" o "boda alquímica", conocido en el lenguaje jungiano como proceso de individuación (Jung, 1989, p.36). Esto conduciría a considerar a ambos personajes como partes de un solo ser representado en un momento de este proceso de integración o conciliación interior. Lectura que, en su dimensión simbólica, es reforzada por los elementos secundarios de la composición. Las vasijas o tinajas, simbolizan el ámbito en el que se produce la mezcla de las fuerzas que dan origen al cosmos y que el alquimista replica en su trabajo de participación en la "obra”. Aluden simbólicamente a la idea de matriz universal, metáfora del útero cósmico en el cual se gesta todo lo existente. La mujer al emerger entre la niebla, lo hace desde lo indiferenciado, necesario entre cada etapa de evolución y desde tres tinajas como símbolo de la idea de síntesis de lo espiritual.

El perro representa la lealtad, que cuando se ubica a los pies de la mujer tiene el sentido de fidelidad matrimonial. Sin embargo (como todos los símbolos) es bastante polisémico siendo también; alegoría del sacerdocio en el simbolismo cristiano, acompañante del muerto en su viaje nocturno, guardián del umbral o puerta del inframundo (Cirlot, 1992, p.359). En "El sueño del alfarero" parece contribuir al sentido de esta "boda alquímica" como fidelidad del alquimista con la "gran obra". Su presencia podría tener también el sentido de psicopompo, guía y conductor en este proceso que incluye la muerte (última obra antes de la muerte del artista). 
La escalera está presente en muchas de las obras de Mourgues. En la narración bíblica del sueño de Jacob representa un puente vertical entre el mundo terrenal y el celestial (Génesis 28:10- 19), es mencionada también en el "El Libro de los Muertos" tibetano, y la tradición islámica señala que Mahoma vio una escalera por la que los justos subían hasta Dios. Aparece en los misterios de Mitra, y en el arte románico es símbolo de la relación entre los mundos. Su aspecto de gradación fue especialmente recogido por la alquimia, desde fines de la Edad Antigua, identificándose dichos grados con las etapas del proceso de transformación. Eliade, con sentido a la vez psicológico, dice que la escalera representa plásticamente la ruptura de nivel que hace posible el paso de un mundo a otro y la comunicación entre cielo, tierra e infierno (o entre virtud, pasividad y pecado). Por ello es también uno de los símbolos más notables del culto a los antepasados (Cirlot, 1992, pp.186-187). En "el sueño del alfarero", simboliza las etapas del proceso de transformación y perfeccionamiento espiritual, trabajo que exige dedicación y paciencia infinita en la soledad del ser. Trabajo que en lo reiterativo y paciente es semejante a la del artesano que repite una y otra vez hasta el infinito su gesto sobre la materia.

Algo más confusa e incierta, es la presencia del toro por los diversos y hasta contradictorios sentidos que se le han asignado como símbolo. Algunos lo relacionan con la tierra, símbolo de la madre y del principio húmedo. Otros, lo consideran símbolo del cielo y del padre (Cirlot, 1992, p. 445). Para Eliade, expresa el cielo fecundador, dice también que el toro y el rayo fueron desde el 2400 a. de C. símbolos concertados de las divinidades atmosféricas (Eliade, 1974, p.116). Según Frobenius, el toro negro es asimilado al cielo inferior, es decir, a la muerte" (Cirlot, 1992, p.445). Las fuentes de la tradición mítica revelan que éste es símbolo de potencia, de fuerza procreativa y que como el sol se identifica con lo masculino. En la obra la función simbólica como elemento fecundador y fuerza procreativa reforzaría el contenido general.

Mourgues presenta en esta obra al "iniciado" absorto en su trabajo de colaboración con la "Gran Obra”. Habla de la actitud de abnegación y perseverancia que la tradición alquímica exige del iniciado que trabaja con paciencia en soledad y silencio, en una tarea que exige del artífice toda su fortaleza para desarrollar la "obra". A través de este personaje — que parece un artesano- representa en realidad un trabajo religioso y de éste, el momento de religar en el "Sí-Mismo" los fragmentos de la dualidad en lo que Jung llama "proceso de individuación".

Rasgos como la ausencia de un espacio "real", la esquematización del cuerpo humano, la reiteración de la circularidad, la coexistencia de los contrarios, el aislamiento en que operan los personajes, la presencia del tercer ojo y otros reconocidos símbolos (perro, toro, escalera, luna, sol, 
vasijas) junto a frecuentes reiteraciones numéricas, adquieren especial relevancia y permiten sostener la hipótesis de que el autor refiere una tradición gnóstica vinculada a la alquimia medieval vista como vía de superación espiritual. Espiritualidad entendida en el contexto de aquellos pensadores de principios del siglo XX, como Ouspensky, Gurdjieff y Steiner entre otros, y que busca promover el despertar del hombre de su "sonambulismo" llevándolo a estados de conciencia más elevados en respuesta al aforismo griego inscrito en el templo de Apolo en Delfos, “Conócete a ti mismo”.

\section{Conclusiones}

La obra de Germán Mourgues al rescatar saberes populares, tradiciones y leyendas locales — lo que ya encierra un valor - mantiene viva la presencia de conocimientos del mito, el rito y la alquimia, conocimientos que han sido olvidados en la actualidad. Aunque podría catalogarse como costumbrista por recurrir a la leyenda y mitología regionales, va más allá del localismo que implica dicho género. Estas resonancias más amplias y profundas se evidencian al abordar su lectura desde el aspecto simbólico de su repertorio visual, emparentándose en este plano con un Puvis de Chavannes o, tal vez, con la pintura mística o metafísica de William Blake.

Al analizar la obra de Germán Mourgues, esta incrementa su espesor y multiplica sus lecturas sorprendiendo por su riqueza de contenido y su profunda y honesta originalidad. Todo en su obra parece referir a lo esotérico. En términos de Durand, la obra se expresa en un lenguaje de "régimen nocturno", oscuro, profundo, simbólico y subjetivo. Por lo que siempre quedará una parte vedada a nuestra mirada, en ese juego propio del símbolo que devela y oculta simultáneamente.

Es posible ver en la obra de Mourgues la representación de un sentimiento de descontento frente a una civilización (en crisis) que ha sido construida sobre la adoración de la técnica, la sobrevaloración de la ciencia y la supremacía de los valores materiales y que ha roto con la primordial armonía entre cuerpo y alma, con la unidad originaria entre pensamiento mágico y pensamiento lógico, en suma, con la comunión entre el hombre y el cosmos.

La originalidad y autenticidad de su propuesta artística, tanto en la forma como en el contenido, son valores que la convierten en un producto único tanto a nivel local como global que justifica el rescate, conservación y puesta en valor de su legado y su consideración como parte del patrimonio cultural de la comunidad.

Sin duda, son muchos los aspectos que han quedado sin abordar en este trabajo, pues la riqueza de la obra de Germán Mourgues es inagotable y las obras estudiadas son una pequeña parte 
de su producción. Aun así, las obras elegidas han permitido ilustrar algunas ideas sobre su obra y el valor que estas encierran.

\section{Referencias bibliográficas}

CIRLOT, Eduardo (1992). Diccionario de símbolos. Ed. Labor: Barcelona.

ELIADE, Mircea (1974). Tratado de historia de las religiones. Ed. Cristiandad; Madrid.

ELIADE, Mircea (1983). Herreros y alquimistas. Alianza Editorial: Madrid.

ELIADE, Mircea (1999). Historia de las creencias y las ideas religiosas. Paidós: Barcelona.

JUNG, Carl Gustav (1970). Arquetipos e inconsciente colectivo. Paidós: Barcelona.

JUNG, Carl Gustav (1977). Psicología y alquimia. Ed. Plaza \& Yanes: Barcelona.

JUNG, Carl Gustav (2012). El libro rojo. Ed. El hilo de Ariadna: Buenos Aires.

PANOFSKY, Erwin (1979). El significado en las artes visuales. Alianza Editorial: Madrid.

KANDINSKY, Wassily (1989). De lo espiritual en el arte. Ed. Premia: Puebla. 